05,11

\title{
Анализ приближения к намагниченности насыщения и динамики размагничивания аморфного спинового стекла PrDyFeCoB
}

\author{
(C) Е.В. Дворецкая ${ }^{1}$, Д.В. Королев ${ }^{1,2}$, О.В. Коплак ${ }^{1}$, Р.Б. Моргунов ${ }^{1-3}$ \\ ${ }^{1}$ Институт проблем химической фризики РАН, \\ Черноголовка, Россия \\ ${ }^{2}$ Всероссийский научно-исследовательский институт авиационных материалов, \\ Москва, Россия \\ ${ }^{3}$ Тамбовский государственный технический университет, \\ Тамбов, Россия \\ E-mail: o.koplak@gmail.com
}

Поступила в Редакцию 2 июля 2021 г.

В окончательной редакции 2 июля 2021 г.

Принята к публикации 3 июля 2021 г.

\begin{abstract}
Представлен анализ полевой и временной зависимостей намагниченности аморфно-кристаллических микропроводов $\operatorname{PrDyFeCoB}$ Установлено, что кривая намагниченности вблизи поля насыщения имеет более плавное приближение к насыщению, чем в ферромагнетике, что согласуется с теоретическими предсказаниями для спин-стекольного состояния сплава в аморфном состоянии в рамках модели случайной магнитной анизотропии. Обнаружены отклонения динамики релаксации намагниченности микропроводов от логарифмической временной зависимости и исчезновение этой разницы при наблюдении магнитной релаксации в магнитном поле. Это свидетельствует о типичной динамике перемагничивания спинового стекла в нулевом поле и ферромагнитном характере размагничивания в поле, отличном от нуля. Полученные результаты свидетельствуют о наличии в микропроводах PrDyFeCoB экзотического магнитного состояния материала со стохастической локальной магнитной анизотропией.
\end{abstract}

Ключевые слова: спиновое стекло, ферримагнетик, редкоземельные сплавы, случайная магнитная анизотропия.

DOI: $10.21883 /$ FTT.2021.11.51590.158

\section{1. Введение}

Спиновые стекла с высокой локальной магнитной анизотропией давно привлекают внимание, как новые среды с необычными магнитными свойствами. Примером таких материалов могут служить аморфные сплавы интерметаллидов DyFeB, интенсивно исследуемые некоторое время назад [1-5]. Характерной особенностью этой группы сплавов является значительная энергия одноионной магнитной анизотропии $D$, сильно превышающая энергию обменного взаимодействия ионов $J$. Выполнение условия $D \gg J$ приводит к такой ситуации в аморфном материале, при которой вариации магнитной анизотропии и хаотизация осей анизотропии в отдельных ионах приводят к беспорядку намагниченности, а не вариации межатомных расстояний $r$, модулирующие величину обменного взаимодействия $J(r)[1]$. Значительная асимметрия одноионной анизотропии в редкоземельных сплавах приводит к появлению в них специфических состояний спинового стекла, таких как изинговское спиновое стекло, а также к появлению спин-переориентационных переходов, вызываемых сравнительно слабым магнитным полем. Отметим, что физическая природа спинового стекла с редкоземельными ионами отличается от спинстекольных состояний в аморфных сплавах на основе переходных металлов (FeSi, FeCoSi и т.п.), в которых атомный беспорядок создает хаотичность в распределении величины обменного взаимодействия $J(r)$, а не магнитной анизотропии.

В работах [6,7] был обнаружен спин-переориентационный переход в микропроводах PrDy-FeCo-B, который заключается в резком росте магнитного момента микропровода в 3-10 раз при приложении магнитного поля 100-1000 Ое вдоль микропровода при $250 \mathrm{~K}$. При других температурах требовалось другое критическое поле, так что зависимость критической температуры этого перехода от критического поля переключения состояний подчинялась известному закону Альмейды-Таулеса, полученному теоретически для спиновых стекол с высокой магнитной анизотропией [8]. Сплав PrDy-FeCo-B в кристаллических фазах 2-14-1, 1-4-1 идр. является изоструктурным ранее исследованному сплаву DyFeB, в котором был обнаружен теоретически предсказанный переход Альмейды-Таулеса. Различие заключается лишь в том, что в подрешетке переходных металлов часть ионов железа замещается ионами $\mathrm{Co}^{2+}$ с большей анизотропией, а в редкоземельной подрешетке часть ионов $\mathrm{Dy}^{3+}$ замещены близкими к ним ионами $\mathrm{Pr}^{3+} \mathrm{c}$ несколько меньшими значениями одноионной анизотропии. В остальном, также как в работах [1-5], в аморфных микропроводах проявляется спин-переориентационный переход между спин-стекольным (SSG) и ферримагнит- 
ным (FM) состояниями. Физические процессы, лежащие в основе такого перехода, были рассмотрены с помощью кластерной теории перколяций (или теории протекания) [9], которая применяется к островкам аморфного материала, возникших случайным образом в результате корреляции осей одноионной анизотропии в локальных областях материала [10]. Увеличение магнитного поля ведет к росту таких островков и постепенному распространению ферримагнитных областей, вытесняющих спин-стекольное состояние. При уменьшении температуры преодоление барьера магнитной анизотропии осложняется, и требуется все большее поле для переключения в ферримагнитное состояние. Выполнимость предсказаний Альмейды-Таулеса для границы такого перехода в пространстве поле-температура $(H-T)$ была проверена нами в предыдущих работах, подтвердивших переход $\mathrm{SSG} \rightarrow$ FM $[6,7]$.

Еще одним признаком спин-стекольного состояния, даже более общим, пригодным для спиновых стекол разного типа, являются: более плавный подход к намагниченности насыщения $M_{S}$ при увеличении магнитного поля [11], а также специфические временные зависимости намагниченности при изменении внешнего поля, отличные от логарифмической зависимости [7], наблюдаемой в структурно-несовершенных ферромагнетиках. Приближение намагниченности к насыщению в аморфных ферромагнетиках изучалось в работах Кронмюллера [10,12,13], а также анализировалось в работах Чудновского с соавторами [14-17], которые предложили объяснение этому явлению на основе представлений о хаотическом распределении обменного взаимодействия. В работе [18] были получены аналогичные теоретические объяснения кривым намагничивания для ситуации, когда хаотичным является распределение магнитной анизотропии по величине и знаку.

Целью настоящей работы являлись проверка формы полевых зависимостей намагниченности при приближении к насыщению (в сильных полях) в аморфных микропроводах, а также установление временных зависимостей самопроизвольного размагничивания аморфных микропроводов $\mathrm{PrDyFeCoB}$ и их сравнении с магнитной релаксацией ферромагнитного состояния, индуцированного полем в этом же микропроводе $\mathrm{PrDyFeCoB}$.

\section{2. Методика и образцы}

Аморфные микропровода с объемной долей аморфного материала до $86 \%$, были получены сверхбыстрым охлаждением капли расплава PrDyFeCoB на вращающемся медном цилиндре, охлаждаемом водой. Скорость охлаждения расплава в аналогичных условиях составляет обычно $10^{6} \mathrm{~K} / \mathrm{s}$ [7]. Каплю расплава получали на острие спеченного магнита при его разогреве электронным пучком. Быстрое вращение цилиндра с линейной скоростью поверхности $50 \mathrm{~m} / \mathrm{s}$ вытягивало расплав, затвердевающий в форме микропроводов, близ-

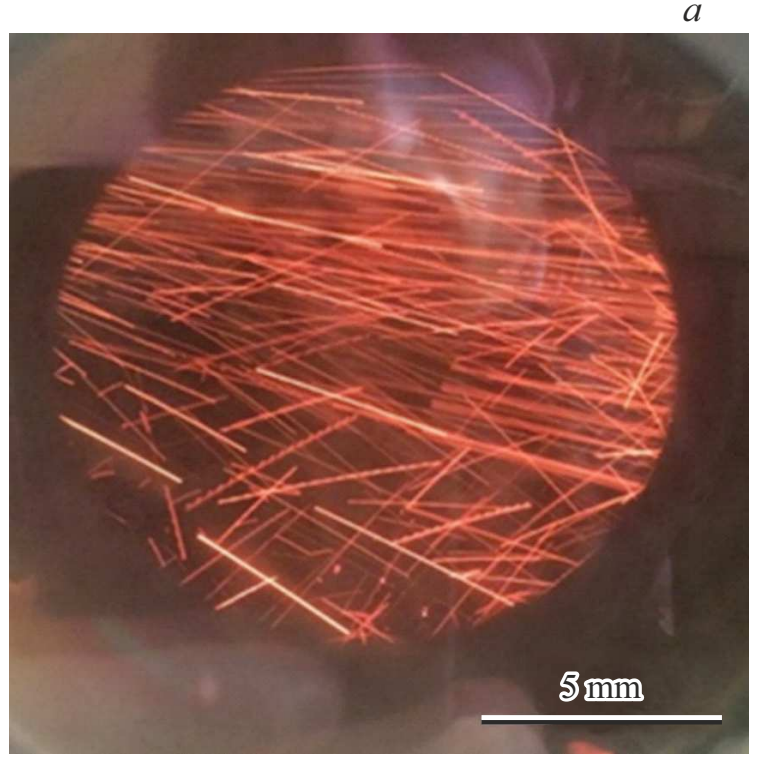

b

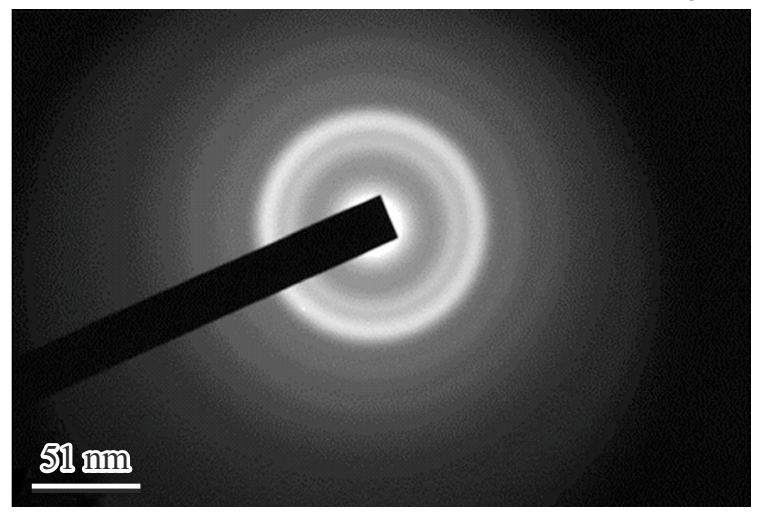

Рис. 1. (а) Формирование микропроводов в процессе вытягивания расплава на охлаждающем цилиндре. $(b)$ Электроннодифракционное изображение, полученное для ламели, вырезанной из микропровода (ширина щели $51 \mathrm{~nm}$ ).

кой к цилиндрической, длиной 10-20 mm и диаметром 50-100 $\mu \mathrm{m}$ (рис. $1, a$ ). Ранее нами сообщалось об исследовании химического и фазового состава микропроводов с помощью просвечивающей электронной микроскопии (TEM), рентгено-дифракционного анализа (XRD), фазового контраста отраженных электронов (BSE), рентгеновской фотоэлектронной спектроскопии (XPS) и энерго-дисперсионных спектров (EDX), полученных в сканирующем электронном микроскопе (SEM) [6,7].

Мы использовали просвечивающий электронный микроскоп высокого разрешения HR TEM JEOL для получения электронно-дифракционных изображений, с помощью которых можно было убедиться, что основной объем микропроводов составляет аморфная фаза, демонстрирующая гало (рис. 1,b). Интегральный магнитный момент микропровода и его зависимости от поля и времени были записаны в SQUID-магнетометре MPMS XL Quantum design при $300 \mathrm{~K}$. 


\section{3. Экспериментальные результаты}

Зависимость магнитного момента микропровода от магнитного поля показана на рис. 2, $a$. Видно, что приближение к насыщению характеризуется длинным пологим участком кривой $M(H)$, не характерным для ферромагнитного состояния. Для проверки выполнимости предсказаний теории участок, в котором $M / M_{S}>0.85$ (как это обычно делается в работах, посвященных анализу полевой зависимости намагниченности), был построен в координатах $M\left(1 / H^{2}\right)$, в которых наблюдалось спрямление полевой зависимости магнитного момента (рис. 2, $b$ ).

Далее нами проведены опыты по исследованию релаксации магнитного момента в разных условиях. В первой серии опытов поле от величины $+1 \mathrm{kOe}$ скачком переключалось к нулевому значению, и после установления нулевого значения (примерно за $40 \mathrm{~s}$ ) начиналась запись зависимости магнитного момента от времени. Результа-
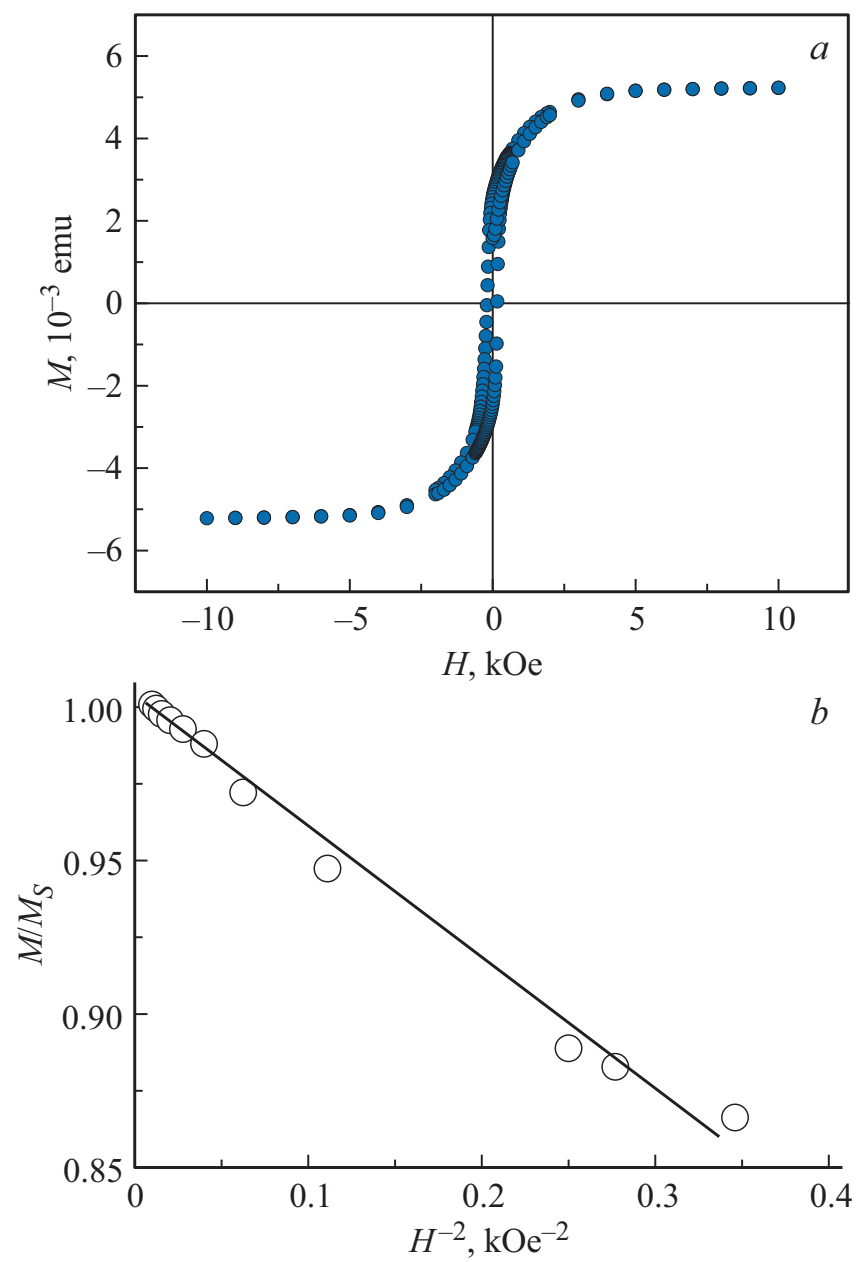

Рис. 2. Зависимость магнитного момента микропровода от магнитного поля $(a)$, и полученный из нее фрагмент зависимости приведенного к намагниченности насыщения магнитного момента $M / M_{S}$ от величины $1 / H^{2}(b)$. Сплошной линией показана аппроксимация, обсужденная в тексте.
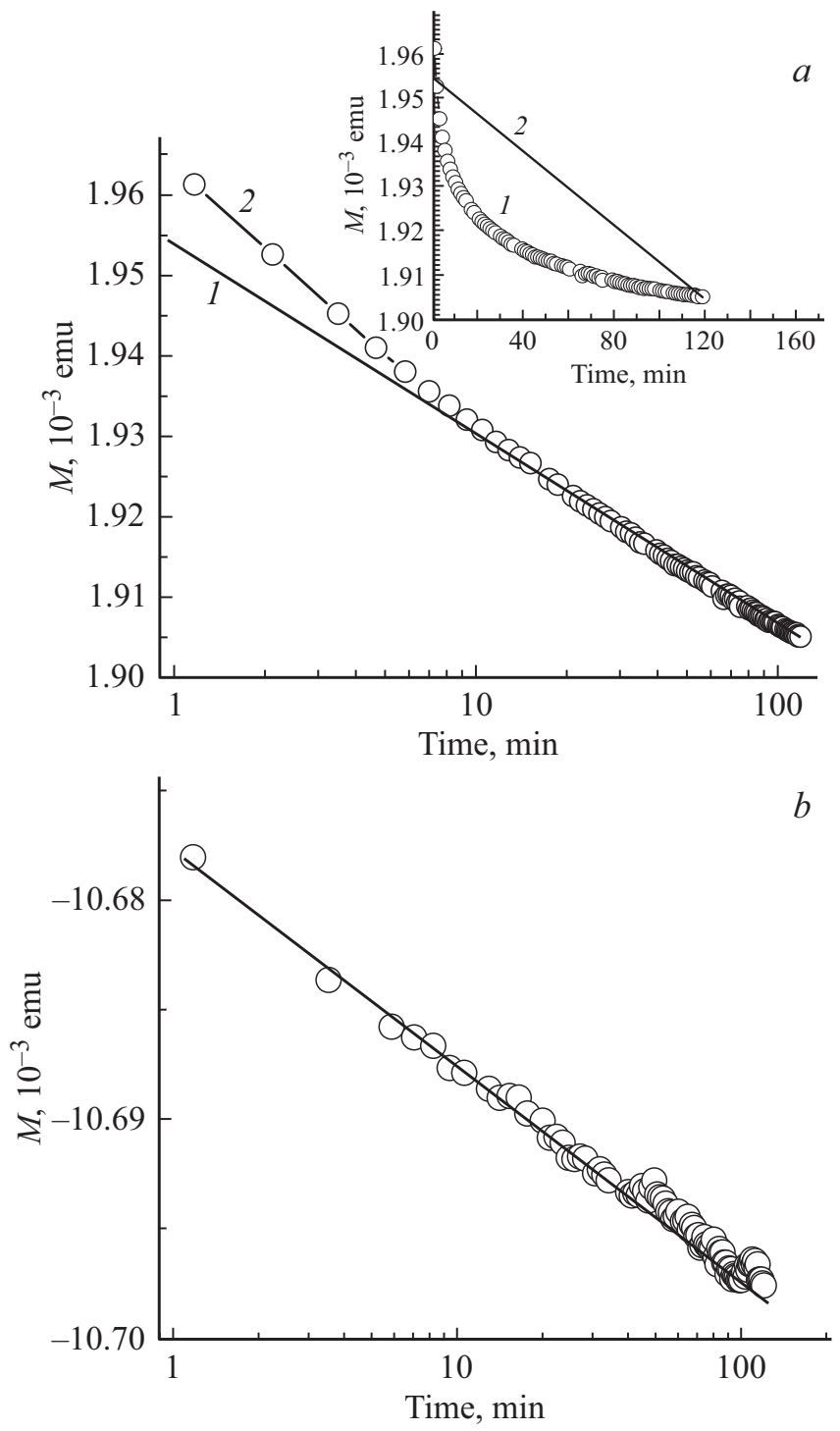

Рис. 3. (а) Зависимость магнитного момента микропровода от времени после выключения магнитного поля $1 \mathrm{kOe}$ до нуля. Сплошной линией 1 показана логарифмическая зависимость $M=S_{0} \ln (t / \tau)$, а сплошная линия 2 - аппроксимация формулой (5), описанной в тексте. На врезке показана та же зависимость с логарифмическим масштабом по вертикальной оси и линейным масштабом по горизонтальной оси. $(b)$ Зависимость магнитного момента микропровода от времени после переключения поля от $+1 \mathrm{kOe}$ к отрицательному значению $-1 \mathrm{kOe}$. Сплошной линией показана логарифмическая зависимость $M=S_{0} \ln (t / \tau)$.

ты показаны на рис. 3, $a$. Видно, что в полулогарифмических координатах эта зависимость не спрямляется, хотя при исследовании нами поликристаллических магнитов близкого химического состава, это спрямление имело место [19]. Таким образом, в нулевом магнитном поле, когда ожидаемо, что аморфный микропровод пребывает в спин-стекольном состоянии, магнитная релаксация его магнитного момента отличается от логарифмической релаксации ферримагнетика. 
Во второй серии опытов, направленных на исследование динамики магнитной релаксации, магнитное поле от значения +1 kОе скачком переключали к отрицательному значению $-1 \mathrm{kOe}$ (т. е. меняли направление внешнего магнитного поля). Поскольку ранее было установлено, что при высоких температурах в магнитном поле $1 \mathrm{kOe}$ происходит переход $\mathrm{SSG} \rightarrow \mathrm{FM}$, можно было ожидать, что микропровод в магнитном поле, большем порогового значения, находится в ферримагнитном состоянии. На рис. 3, $b$ показана релаксация магнитного момента микропровода, записанная после переключения поля от $+1 \mathrm{kOe}$ к $-1 \mathrm{kOe}$. Видно, что в таком же диапазоне времен, что и в первой серии опытов, наблюдается логарифмическая зависимость магнитного момента от времени, наблюдаемая ранее в поликристаллических материалах близкого химического состава [20].

Таким образом, в аморфных микропроводах $\operatorname{PrDyFeCoB~наблюдается~медленное~приближение~на-~}$ магниченности к насыщению с ростом магнитного поля, а также отклонение временной зависимости перемагничивания от логарифмической зависимости в нулевом магнитном поле.

\section{4. Обсуждение экспериментальных результатов}

Согласно теории Е.M. Чудновского с соавторами, полевая зависимость изменения магнитного момента образца $\Delta M$ должна соответствовать следующим предсказаниям. В „слабых“ полях, меньших величины обменного взаимодействия, выраженного в единицах поля, т. е. при $H \ll H_{\text {ex }}$ :

$$
\Delta M / M_{S}(H)=v / 30\left(H_{\mathrm{r}} / H_{\mathrm{ex}}\right)^{2}\left(H_{\mathrm{ex}} / H\right)^{1 / 2},
$$

в „сильных“ полях, больших величины обменного взаимодействия, т. е. при $H \gg H_{\text {ex }}$ :

$$
\Delta M / M_{S}(H)=1 / 15\left(H_{\mathrm{r}} / H\right)^{2} .
$$

Мы воспользовались выражением (2), чтобы построить зависимость $M\left(1 / H^{2}\right)$, и убедились в его справедливости (рис. 2,b).

Переходя к обсуждению зависимости намагниченности от времени, отметим, что классическая функция, описывающая релаксацию ферромагнетиков с широким спектром препятствий доменных стенок (с равно распределенной плотностью вероятности амплитуды препятствий), подчиняется обычно логарифмической зависимости

$$
M(t)=S_{0} \ln (t / \tau),
$$

где $S$ - постоянная величина, называемая магнитной вязкостью, а $\tau$ - константа, характеризующая длительность процесса. Такая зависимость должна была бы спрямляться в полулогарифмических координатах
$M \sim \lg (t / \tau)$, однако из рис. $3, a$ следует, что спрямление отсутствует (сплошная линия 1 на рис. $3, b$ соответствует функции (3)). В совершенном ферромагнетике это могло бы говорить о том, что энергетический спектр препятствий отличается от равнораспределения. Однако очевидно, что спеченные магниты такого типа, быстроохлажденный расплав, это объекты с широким спектром препятствий и в них трудно ожидать иного распределения. Кроме того, плотность вероятности энергии препятствий в виде узкой функции, близкой к $\delta$-функции, должна была бы приводить к экспоненциальной зависимости $M(t) \sim \exp \left(-t / t_{0}\right)$. Временные зависимости магнитного момента в спиновом стекле также могут подчиняться экспоненциальной функции с показателем степени $0<n<1$ [4]. При температурах ниже температуры „замерзания“ хаотичных спиновых ориентаций временная зависимость магнитного момента примет вид:

$$
M(t) \sim \exp \left(-t / t_{0}\right)^{n}
$$

Однако, ни чисто экспоненциальная функция, ни экспоненциальная функция со степенью (4) не описывают полученную временную зависимость, поскольку отклонение от прямой в координатах $\lg (M(t))$ становится еще более сильным (см. вставку на рис. 3,a). Еще одним способом описания динамики перемагничивания спинстекольных материалов является функция, полученная в рамках фрактально-кластерной модели, описанной во введении

$$
\partial M / \partial t=A(t / \tau)^{-k} \exp (-t / \tau)^{-k f} .
$$

В этой функции $k$ и $f-$ статические и динамические показатели степени, а $\tau \sim 10^{-13} \mathrm{~s}-$ постоянная времени, характеризующая длительность спинового перехода под действием спиновой релаксации. Аппроксимация зависимости $M(t)$ функцией (5) показана линией 2 на рис. 3, a. Видно, что не только полевая зависимость (рис. $2, b)$, но и временная зависимость (рис. $3, a)$ хорошо описываются в рамках одной и той же фрактальнокластерной модели.

Наконец, возможность инициирования магнитного перехода $\mathrm{SSG} \rightarrow \mathrm{FM}$ магнитным полем, установленная в $[6,7,17]$ говорит о том, что магнитная релаксация в том же микропроводе может оказаться характерной для ферромагнетика, если подавить спин-стекольное состояние полем. Для проверки этого предположения была построена динамика перемагничивания в отрицательном (обратном по направлению) магнитном поле, в котором наблюдалась логарифмическая зависимость $M=S_{0} \ln (t / \tau)$ (рис. 3,b). Этот факт означает, что магнитного поля $1 \mathrm{kOe}$ достаточно, чтобы динамика перемагничивания соответствовала ферримагнетику с широким спектром препятствий для движения доменных стенок.

На рис. 4 показана граница между SSG и FM coстояниями, определенная по резкому скачку магнитного 


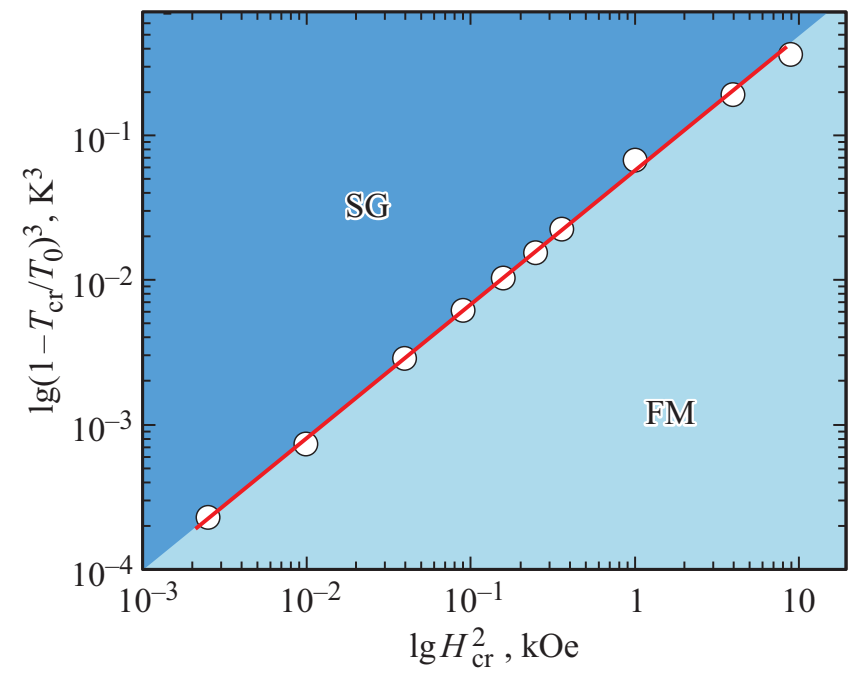

Рис. 4. Граница перехода между спин-стекольным (SSG) и ферримагнитным (FM) состояниями микропровода в пространстве поле-температура $\left(H_{\mathrm{cr}}^{2}-T_{\mathrm{cr}}^{3}\right)$. Сплошной линией показана аппроксимация формулой Альмейды-Таулеса.

момента микропровода, измеряемому в разных температурах и магнитных полях. Эта граница представляет собой зависимость критического поля перехода $H_{\mathrm{cr}}$ от критической температуры перехода $T_{\mathrm{cr}}$. Во многих статьях, посвященных переходу Альейды-Таулеса, зависимость описывается формулой [21]:

$$
H_{\mathrm{cr}}=H_{0}\left(1-T_{\mathrm{cr}}(H) / T_{\mathrm{SG}}(0)\right)^{\alpha},
$$

в которой показатель степени $\alpha$ играет ключевую роль. Он определяет тип спинового стекла. Имеется два предельных случая: гейзенберговское спиновое стекло, характеризуемое значением $\alpha=3 / 2$ и изинговское спиновое стекло, для которого $\alpha$ может отличаться от $3 / 2$. Мы построили зависимость квадрата критического поля $H_{\mathrm{cr}}^{2}$ от куба критической температуры $T_{\mathrm{cr}}^{3}$, чтобы проверить, является ли граница раздела фаз прямой линией в этих координатах. Из рис. 4 следует, что условие перехода $\mathrm{SSG} \rightarrow \mathrm{FM}$ выполняется в исследуемых микропроводах.

\section{5. Выводы}

1) Получены микропровода $\operatorname{PrDyFeCoB}$ с высокой долей аморфной фазы до $86 \%$, в которых приближение намагниченности к насыщению подчиняется известной закономерности $M \sim 1 / H^{2}$, полученной в рамках кластерно-перколяционного подхода для спинового стекла.

2) Динамика перемагничивания в нулевом поле, в котором спин-стекольное состояние не подавлено, подчиняется предсказаниям кластерно-перколяционной теории в спиновых стеклах.

3) Динамика перемагничивания в ненулевом поле $1 \mathrm{kOe}$, в котором спин-стекольное состояние подавлено и произошел переход в ферримагнитное состояние, подчиняется логарифмической зависимости, широко известной для ферромагнетиков с равновероятным распределением энергий препятствий для движения доменных стенок.

4) Полученные данные в совопкупности с обнаруженной ранее границей перехода $\mathrm{SSG} \rightarrow \mathrm{FM}$ свидетельствуют о том, что аморфные микропровода $\mathrm{PrDyFeCoB}$ являются спиновым стеклом с необычным спиновым беспорядком, поддерживаемым не вариациями обменного взаимодействия (как это имеет место в переходных аморфных сплавах), а вариацией случайных направлений локальных осей одноионной анизотропии ионов $\operatorname{Pr}^{3+}$ и $\mathrm{Dy}^{3+}$.

\section{Благодарности}

Авторы выражают благодарность Н.Н. Дремовой и И.И. Ходосу за помощь в получении SEM- и TЕMизображений.

\section{Финансовая поддержка}

Работа выполнена в рамках тематической карты Института проблем химической физики АААА-А19-119092390079-8, при поддержке проекта РФФИ (грант 20-32-70025) и программы грантов Президента РФ для поддержки ведущих научных школ (грант 2644.2020.2).

\section{Конфликт интересов}

Авторы заявляют, что у них нет конфликта интересов.

\section{Список литературы}

[1] B. Dieny, B. Barbara. J. Phys. 46, 293 (1985).

[2] S.J. Pickart, H.A. Alperin, R.J. Gambino, T.R. McGuire. J. Appl. Phys. 55, 1763 (1984).

[3] D.J. Sellmyer, S. Nafis. J. Appl. Phys. 57, 3584 (1985).

[4] И.В.Золотухин, Ю.Е. Калинин. УФН 160, 9, 75 (1990).

[5] R. Harris, M. Plischke, M.J. Zuckerman. Phys. Rev. Lett. 31, 160 (1973).

[6] О.В. Коплак, Е.В. Дворецкая, Д.В. Королев, Р.А. Валеев, В.П. Пискорский, А.С. Денисова, Р.Б. Моргунов. ФТТ 62, 8, 1187 (2020).

[7] O. Koplak, R. Morgunov. Mater. Sci. Eng. B 263, 114845 (2021).

[8] J.R.L. de Almeida, D.J. Thouless. J. Phys. A 11, 983 (1978).

[9] R.R.P. Singh, A.P. Young. Phys. Rev. E 96, 012127 (2017).

[10] H. Kronmüller. J. Appl. Phys. 52, 1859 (1981).

[11] В.А. Игнатченко, Р.С. Исхаков, Г.В. Попов. ЖЭТФ 82, 5, 1518 (1982).

[12] H. Kronmüller, A. Seeger. J. Phys. Chem. Solids 18, 2-3, 93 (1961).

[13] M. Fähnle, H. Kronmüller. J. Magn. Magn. Mater. 8, 2, 149 (1978).

[14] E.M. Chudnovsky, J. Tejada. Eur. Lett. 517 (1993).

[15] J. Tejada, B. Martinez, A. Labarta, E. Chudnovsky. Phys. Rev. B 44, 14, 7698 (1991). 
[16] E.M. Chudnovsky, R.A. Serota. Phys. Rev. B 26, 2697 (1982);

[17] E.M. Chudnovsky, R.A. Serota. J. Phys. C 16, 4181 (1983).

[18] И.Я. Коренблит, Е.Ф. Шендер. УФН 157, 2, 5 (1989).

[19] А.И. Дмитриев, А.Д. Таланцев, Е.И. Куницына, Р.Б. Моргунов, В.П. Пискорский, О.Г. Оспенникова, Е.Н. Каблов. ЖЭТФ 150, 350 (2016).

[20] E. Kunitsyna, O. Koplak, V. Kucheryaev, R. Valeev, D. Korolev, V. Piskorskii, R. Morgunov. J. Appl. Phys. 124, 163906 (2018).

[21] D.J. Sellmyer, S. Nafis. J. Magn. Magn. Mater. 54-57, 113 (1986).

Редактор Ю.Э. Китаев 